\title{
Green economic efficiency and influencing factors analysis of the Yangtze river economic belt in China
}

\author{
Jiani WU \\ School of Economics and Resource Management, Beijing Normal University
}

\begin{abstract}
For a long time, China's economic development ignore the constraints of resources and environmental costs but onesided pursue GDP. In 2014, the State Council issued a document to develop the Yangtze River economic zone into a "green ecological corridor". The green development of the Yangtze River economic zone is of high-profile. This paper attempts to consider the resource and environmental factors into the economic growth, establish a reasonable evaluation of national and regional economic performance of the green economic efficiency indicators. It can be seen from the DEA estimates that the average green economic efficiency of the Yangtze River economic zone per year is more than 0.9. The Tobit panel model shows that there are differences in the factors affecting the green economic efficiency of different area. But overall, there is a "inverted U-type" relationship between green economic efficiency and per capita GDP, urbanization has a positive effect on green economic efficiency but not significant. Besides, foreign direct investment, structure factors, level of science and technology have a negative effect. According to the results of the inspection, this paper puts forward some policy suggestions on weighing the relationship between economic growth and environmental protection, taking a new road to industrialization and narrowing regional differences.
\end{abstract}

\section{Indexing terms/Keywords}

Green Economic Efficiency; DEA; Yangtze River Economic Zone; Tobit

\section{Academic Discipline And Sub-Disciplines}

Economy ; Regional Economy

\section{SUBJECT CLASSIFICATION}

\author{
Regional Economy ; Green economics
}

\section{TYPE (METHOD/APPROACH)}

\author{
Empirical analysis
}

\section{Introduction}

Since China's reform and opening up, China's economic has been rapidly developed, but at the same time its development shows a characteristics of extensive growth mode. Some areas rely on capital investment, energy and labor force, sided pursue GDP, ignoring the constraints of resources and the price of the environment. In 2016, Global Environmental Performance Index (EPI) shows that China is the PM2.5 hardest-hit areas. In the air quality ranking, China ranked second, only better than Bangladesh. In 2004, the National Bureau of Statistics and the Ministry of Environmental Protection set up a green GDP joint task group to study the green GDP accounting. Since the 18th CPC National Congress, General Secretary Xi Jinping has repeatedly pointed out that the green water is the golden mountain. It's easily to see the distinct attitude and firm determination of the party and the government to promote the construction of ecological civilization vigorously.

The State Council issued the "State Council on relying on the golden waterway to promote the development of the Yangtze River Economic Zone" on September 12,2014. The view proposed to the Yangtze River economic zone into a "green ecological corridor" as a demonstration of ecological civilization in China. Yangtze River Economic Zone covers 11 provinces and cities including Shanghai, Jiangsu, Zhejiang, Anhui, Jiangxi, Hubei, Hunan, Chongqing, Sichuan, Yunnan and Guizhou, with an area of about 2.05 million square kilometers. The population and GDP in this area are more than $40 \%$ of the country. The State Council issued the "State Council on relying on the golden waterway to promote the Yangtze River Economic Development Guide" on September 12, 2014, thus, the Yangtze River economic zone construction become a major strategy for regional development in China. The guidance suggests that the Yangtze River Economic Belt should be built into a "green ecological corridor" as a demonstration zone for ecological civilization in China.

The traditional measurement that use GDP to evaluate the economic performance of a given region, is only concerned with the total amount of the economy without considering the negative effects of resource constraints and production on the environment. This paper puts resource and environmental problems into the economic growth, constructs index of economic performance of the country and region reasonably, and develop a more accurate measure of the quality of China's economic growth. It's of great importance to study the green development efficiency of the Yangtze River Economic Zone, examine its influencing factors and put forward specific measures according to the results, which helps to enhance the green development performance of the Yangtze River Economic Zone, promote regional green economic development and the transformation of economic growth mode, as well as better implement the national sustainable development strategies. 


\section{Literature Review}

Due to the limitation of resources, many scholars gradually transferred their focus on economic growth to the economic growth performance. Most scholars use non-parametric DEA method to measure the efficiency, including environmental efficiency, energy efficiency and total factor productivity, ecological efficiency, green economy efficiency, etc.

Chow and Lin (2002) used the C-D production function to analyze the contribution of total factor productivity of economic growth in Taiwan and mainland China. Yan PengFei, Wang bing(2004) use the DEA method to measure the provincial technical efficiency, technological progress and Manquist productivity index in China. Wang Zhigang et al. (2006) used the stochastic frontier model of logarithmic production function to study the influencing factors and uncertainties of regional production efficiency and production efficiency. The studies above have yielded valuable conclusions, but do not take into account the impact of resource and environmental factors on total factor productivity, whose results will distort the assessment of social welfare and economic performance and may be mislead policy recommendations (Hailu et al, 2000) As environmental issues become more prominent, many scholars begin to incorporate resources and environmental factors into performance considerations. Pittman(1983) developed the super-logarithmic productivity index proposed by Caves et al.(1982), which was the first attempt to introduce environmental factors in efficiency and productivity measures when measuring the efficiency of Wisconsin paper mills. Since then, a large number of researchers began to incorporate environmental pollution variables into the production model to be estimated, there are two main ideas: one is to put the pollution variable as an input; the other is put the pollution variable as a weak disposable "bad" output. However, the first idea not only does not conform to the actual production process, but also violates the theoretical assumptions that the inputs are highly disposable, besides, the production possibilities are bounded.

At present, the product is divided into expected products and non-expected products have become a common recognition, resource and environmental factors have been incorporated into the macro-synergies can be highlighted in China's regional economic efficiency and productivity research.

Yang Long, Hu Xiaozhen(2010) proposed the concept of green economic efficiency. The entropy method was used to construct the comprehensive environmental pollution index of each region, and it was introduced into the economic efficiency measure model to analyze regional differences and convergence. Qian Zhengming, Liu Xiaochen(2013) elaborated the connotation of green economic efficiency for the first time, and used the non-radial non-angle SBM model of DEA efficiency model to measure the green economic efficiency of China's provinces and autonomous regions from 1996 to 2010. They find it was lower than that of traditional Economic efficiency value, and has a "inverted U" relationship with per capita GDP. Liu et al. (2013) used non-expected output SBM model to measure green energy efficiency. Yin et al. (2014) brought environmental pollutants into the ultra-efficient DEA, and use ecological efficiency as a quantitative indicator to assess the sustainable development capacity of 30 cities in China. The results showed that most of the ineffective cities gathered in the economically underdeveloped area such as southwest and northwest area. Wang Xiaoyun, Wei Qi and Hu Xianhui(2016) put environmental pollution together with labor, capital and land as an input index into the efficiency evaluation system.

\section{The Yangtze river economic belt of green economic efficiency analysis and its regional differences}

\subsection{DEA model}

This paper uses DEA model to measure the green economic efficiency of nine provinces and two cities in Yangtze river economic belt. Data Envelopment Analysis (DEA) was first proposed by Chames, Cooper and Rhodes in 1978 mainly used for multi-input efficiency evaluation. The basic idea is to consider the economic system or a complete production process as a decision-making unit (DMU), examine the decision-making unit from input to the output process, and then evaluate the evaluation group consists of the homogeneous DMU, analyze the various inputs or production ratio to get the relative efficiency of each DMU value. Grosskopf (1997) first proposed the concept of network DEA and established DEA model based on network production process, Wang, Gopal, Zionts in 1997 proposed DEA model based on two-stage production process. Thus, the DEA model is defined as:

$$
\mathrm{H}_{\mathrm{j}_{=}} \frac{\sum_{\mathrm{r}=1}^{\mathrm{n}} \mathrm{u}_{\mathrm{r}} \mathrm{y}_{\mathrm{rj}}}{\sum_{\mathrm{i}=1}^{\mathrm{m}} \mathbf{v}_{\mathrm{i}} \mathrm{x}_{\mathrm{ij}}}
$$

where $\mathrm{X}_{\mathrm{ij}}$ refers to the total input amount of $\mathrm{DMU} \mathrm{j}$ to the input of $\mathrm{i}$-type, $\mathrm{m}$ refers to the type of input, ${ }^{\mathrm{i}}$ represents the weighting coefficient for the i-input item, ${ }^{y_{r j}}$ refers to the total output amount of DMU $j$ to the output of $r$-type, $n$ refers to the output type, ${ }^{u_{r}}$ represents the weighting coefficient for the $r$-th output item, ${ }^{j}$ refers to the relative efficiency of the $j$ decision unit, and satisfying $0 \leq \mathrm{H}_{\mathbf{j}}$. Because of the green economic efficiency in this paper is comprehensive efficiency leaving out the pure technical efficiency and scale efficiency. Thus the C2R model satisfies the application conditions, here round of DEA follow-up development, such as BC2 and other models.

\subsection{Indicator selection and data sources}

From the point of view of decision-making science, both input and output can be used as indicators of the object to be evaluated, and people always want to invest less and output more. But inputs and outputs can be divided into Desirable

2338 | P a g e

April, 2017 
and Undesirable inputs and outputs. According to the green economic efficiency calculation method proposed by Qian Zhengming and Liu Xiaochen (2013) this paper adopts four types of indicators: non-resource input factors (labor force, capital stock), resource input factors (energy consumption), expected output (GDP) and non-expected output (industrial "three wastes"). The specific index system is shown in Table 1.

Table 1.Green Economic Efficiency Index System

\begin{tabular}{|l|c|c|}
\hline Indicator type & First class target & Second class target \\
\hline \multirow{3}{*}{ Input variable } & Non-resource input & Labor(X1) \\
\cline { 2 - 3 } & & Capital stock(X2) \\
\cline { 2 - 3 } & Resource input & Energy consumption(X3) \\
\hline \multirow{3}{*}{ Output variable } & Expected output & GDP (Y1) \\
\cline { 2 - 3 } & Non-expected output & Industrial solid waste (Y2) \\
\cline { 2 - 3 } & \multirow{2}{*}{ Industrial wastewater discharge (Y3) } \\
\cline { 2 - 3 } & & Industrial emissions (Y4) \\
\hline
\end{tabular}

While the labor force input index is the total number of employees in a year. Since the capital stock can not be obtained directly from the statistical yearbook, according to the method proposed by Hu \& Kao and Chien \& Hu, this paper use the perpetual inventory method to calculate the capital stock: $\mathrm{Kt}+1=(1-\delta) \mathrm{Kt}+\mathrm{It}$. Where $\mathrm{Kt}$ is the capital stock of $\mathrm{t}$ period, It is the investment of $t$ period that was replaced by the total amount of fixed capital. $\delta$ is the depreciation rate of capital. The calculation of the initial capital stock, the depreciation rate and the fixed capital investment price index are based on the practice of the Shan Haojie(2008).

This paper chooses the annual data of the nine provinces and two cities in the Yangtze River economic belt in China from 2005 to 2014 to calculate the green economy efficiency and its influencing factors. The data are mainly from the China Statistical Yearbook, China Environmental Statistical Yearbook, China Energy Statistical Yearbook, and statistical yearbooks of provinces and municipalities.

\subsection{Green economic efficiency results} to 2014

Table 2 shows the green economic efficiency values of 11 provinces and cities in the Yangtze River Delta from 2005

Table 2.Green economic efficiency of the Yangtze River Delta (2005 - 2014)

\begin{tabular}{cccccccccccc}
\hline Province & $\mathbf{2 0 0 5}$ & $\mathbf{2 0 0 6}$ & $\mathbf{2 0 0 7}$ & $\mathbf{2 0 0 8}$ & $\mathbf{2 0 0 9}$ & $\mathbf{2 0 1 0}$ & $\mathbf{2 0 1 1}$ & $\mathbf{2 0 1 2}$ & $\mathbf{2 0 1 3}$ & $\mathbf{2 0 1 4}$ & Mean \\
\hline Shanghai & 0.94 & 0.92 & 0.98 & 0.99 & 1.00 & 1.00 & 1.00 & 0.99 & 1.00 & 1.00 & 0.98 \\
Jiangsu & 0.89 & 0.69 & 0.76 & 0.78 & 0.80 & 0.83 & 0.68 & 0.72 & 0.84 & 0.81 & 0.78 \\
Zhejiang & 0.99 & 1.00 & 0.98 & 0.97 & 0.97 & 0.94 & 0.99 & 0.98 & 1.00 & 1.00 & 0.98 \\
Anhui & 1.00 & 1.00 & 0.99 & 0.95 & 0.96 & 0.96 & 0.94 & 0.94 & 0.92 & 0.82 & 0.95 \\
Jiangxi & 0.88 & 0.86 & 0.89 & 0.92 & 0.98 & 0.98 & 0.97 & 0.99 & 1.00 & 0.98 & 0.94 \\
Hubei & 1.00 & 0.99 & 1.00 & 0.99 & 0.97 & 0.94 & 0.91 & 0.92 & 0.95 & 0.92 & 0.96 \\
Hunan & 0.97 & 1.00 & 1.00 & 1.00 & 0.97 & 0.95 & 0.96 & 0.98 & 1.00 & 1.00 & 0.98 \\
Chongqing & 0.79 & 0.81 & 0.70 & 0.68 & 0.78 & 0.85 & 0.96 & 1.00 & 1.00 & 1.00 & 0.86 \\
Sichuan & 1.00 & 0.88 & 0.87 & 0.90 & 0.93 & 0.90 & 0.92 & 0.95 & 1.00 & 1.00 & 0.94 \\
Guizhou & 1.00 & 1.00 & 1.00 & 1.00 & 0.99 & 1.00 & 0.97 & 0.98 & 0.97 & 0.99 & 0.99 \\
Yunnan & 1.00 & 1.00 & 1.00 & 0.99 & 0.97 & 0.95 & 0.94 & 1.00 & 0.99 & 1.00 & 0.98 \\
Mean & 0.95 & 0.92 & 0.92 & 0.92 & 0.94 & 0.94 & 0.93 & 0.95 & 0.97 & 0.96 &
\end{tabular}

Note: The efficiency value equal to one indicates that it is efficient; on the contrary, the lower the value is, the lower the efficiency. 


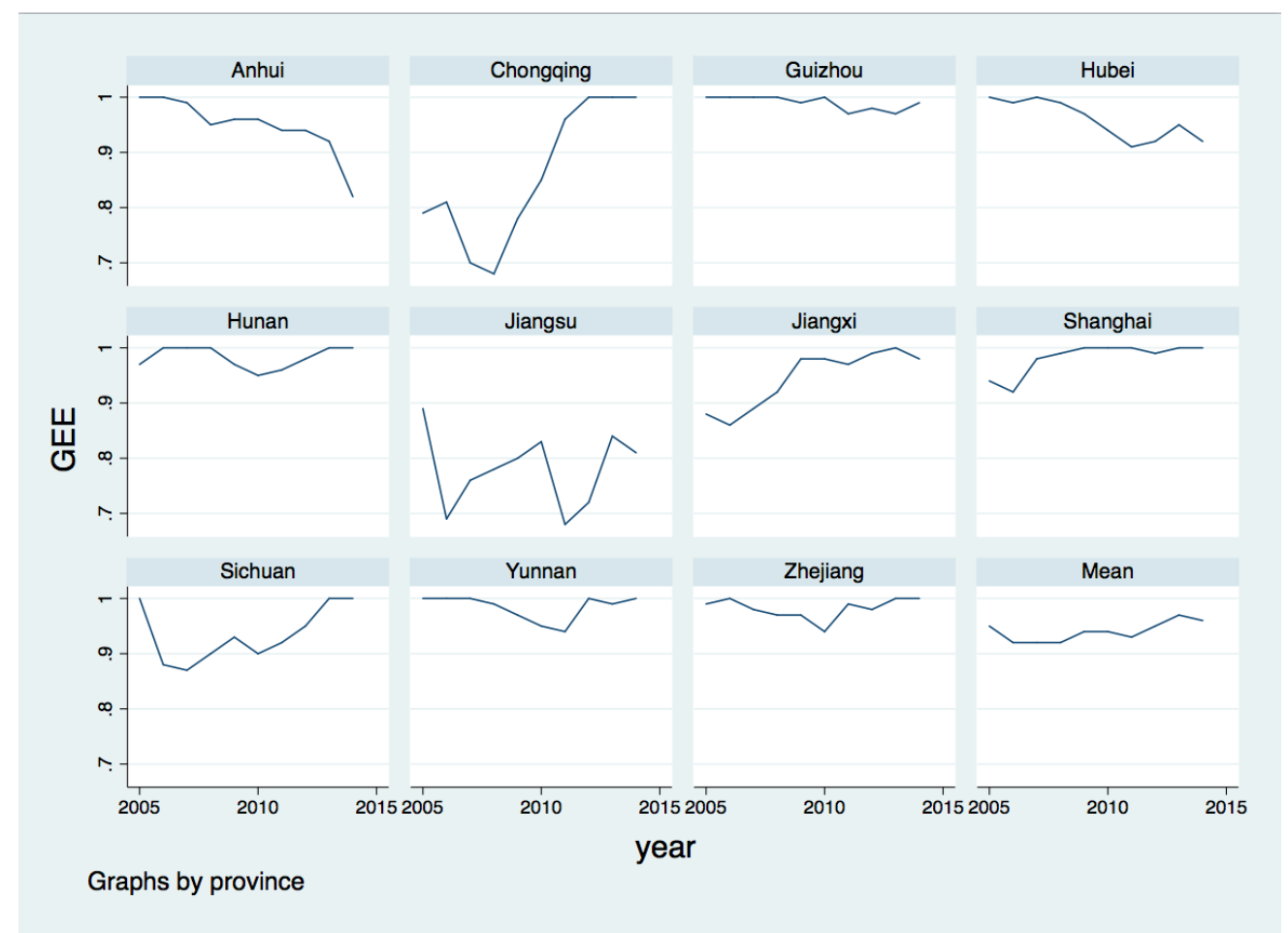

Fig.1 Changes of Green Economic Efficiency in Yangtze River Economic in China

It can be seen from Fig. 1 that the green economic efficiency of the Yangtze River Economic Belt in the period from 2005 to 2014 has been above 0.9 , although there is a slight fluctuation, but the overall upward trend indicates that the green economic efficiency of the Yangtze River economic zone is good.

In recent decades Shanghai's green economic efficiency has shown an upward trend, and reached an effective state around 2009. Jiangsu's green economic efficiency fluctuations, and there are two substantial movements. Zhejiang is generally stable among all the provinces, reaching an effective state during 2013 and 2014 .

Anhui and Hubei show a downward trend, especially in Anhui, the green economy efficiency in 2014 decreased by $10 \%$ than in 2013, which may be related to that Anhui to accept industrial transfer from the Yangtze River Delta region. Jiangxi experienced a steady increase during this decade, which shows that the overall performance in Jiangxi is good after the implementation of a series of changes in economic development, industrial structure adjustment. As for Hunan, Guizhou and Yunnan province, the green economic efficiency is basically in an effective state. Chongqing's green economic efficiency value showed a U-shaped growth, the lowest level is in 2008 , then followed by an increase until reach a basic effective state in 2012.

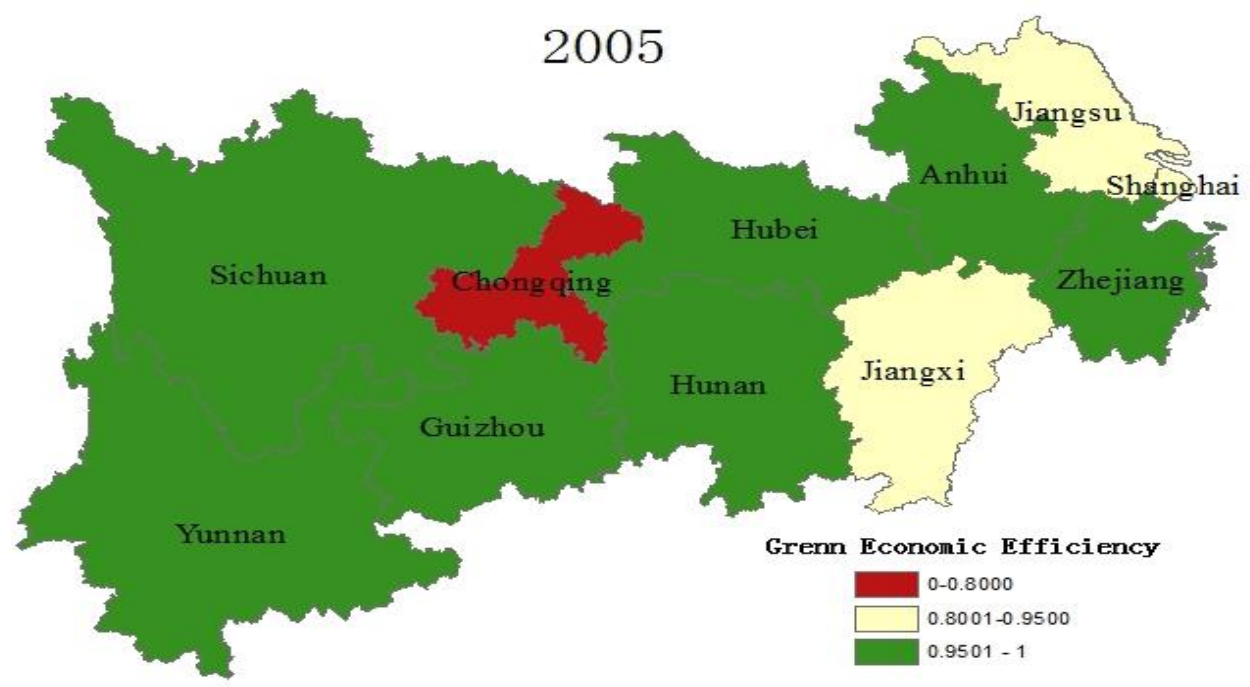

Fig.2a the year of 2005 


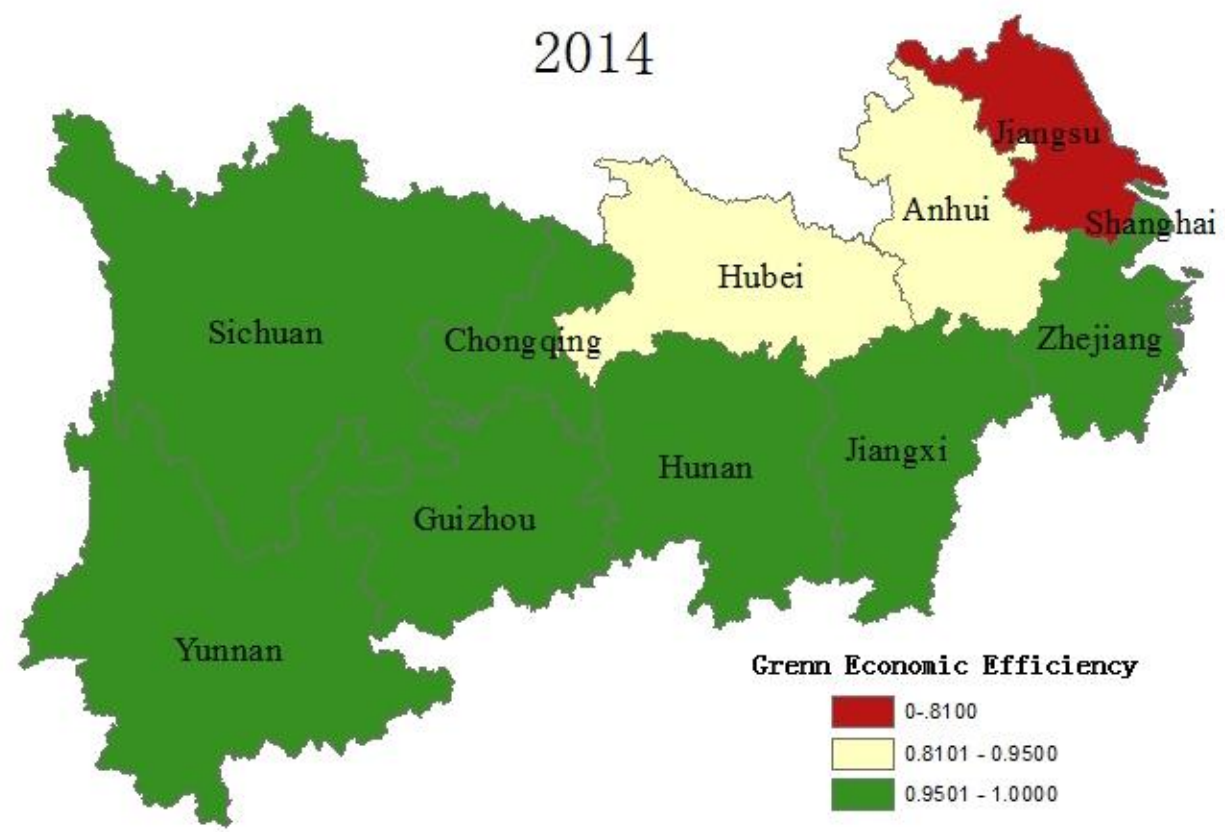

Fig.2b the year of 2014

Fig.2 Space distribution of green economic efficiency in Yangtze River Economic Belt

Figure 2 shows the spatial distribution of green efficiency in the Yangtze River Economic Zone in 2005 and 2014. According to the efficiency range, the provinces and municipalities are divided into three categories. The green efficiency value range from 0.95 to 1 is the very effective area of green economy. 0.8 to 0.95 is relative effective area, while 0.6 to 0.80 .8 is effective area (all the value are more than 0.6 ). When in the year of 2008 , only Chongqing is less than 0.8 . In 2014 , the lowest green economic efficiency is Jiangsu, which was 0.81 . Besides, Shanghai and Jiangxi developed from a relative effective area to a very effective area. On the contrary, the green economic efficiency of Anhui and Hubei decreased, but overall, the very effective area in 2014 was increased compared to the year of 2005.

\section{Analysis on the Influencing Factors of Green Economic Efficiency in Yangtze River Economic}

\subsection{Variable and model}

Because of the Yangtze River economic belt spans cross three zones of East, middle and West in China. The provinces and cities in different regions have variant in the development level and economic characteristics. To explore the factors that affect the green economic efficiency, this paper uses the Tobit panel model to establish a regression model for analysis in the upstream, midstream and downstream areas 1 . With reference to the study of domestic and foreign literature, this paper selects the following variables:

(1) Economic development level: represented by per capita GDP logarithm ((LnGDP)2), this paper intended to investigate whether economic efficiency has a "inverted U" relationship with per capita GDP.

(2) Structural factors: the secondary industry output value of the proportion of GDP is considered as industrial structure (INDSH). The capital and labor ratio of the logarithm $(\mathrm{KL})$ represents endowment structure. Usually the bigger the proportion of the second industry, the lower the green economic efficiency is. While the impact of endowment structure on green economic efficiency is uncertain.

(3) Foreign direct investment (FDI): FDI inflows often strengthen the industry's resource dependence, and technology spillovers can improve the local production and pollution management level. Many literatures have discussed the role of FDI, but there is no uniform conclusion. FDI is expressed as the proportion of foreign direct investment in GDP, and the impact is uncertain.

(4) Technology investment (TEC): science and technology is the primary productive force. They may have an impact on green economic efficiency. In this paper, the expenditure of science and technology in the proportion of GDP represents technology investment, and the expected impact is positive.

${ }^{1}$ According to the traditional distribution, upstream: Yunnan, Sichuan, Chongqing and Guizhou; midstream: Hubei, Hunan, Jiangxi and Anhui; downstream: Jiangsu, Zhejiang and Shanghai.
2341 | P a g e
D O I: 10.24297 / jssr.v11i2.6049
April, 2017
w w w . cir world. co m 
(5) Urbanization level (URBAN): compare to rural areas, city's resource dependence is more prominent, while city have a technical advantage to improve resource use efficiency and pollution control level. Thus, the level of urbanization in each region may have an impact on green economic efficiency. This paper selects the proportion of non-agricultural population as the representative of the level of urbanization. The expected impact is uncertain.

Green economic efficiency is a restricted variable range from 0 to 1 . The regression result can be positive and inconsistent if use the traditional linear method. Therefore, this paper adopts the Tobit panel model with limited dependent variable to analyze the influencing factors of economic efficiency. Based on the above analysis, we can set the following panel regression model

$$
G E E_{i t}=\beta_{0}+\beta_{1} \ln \mathrm{GDP}+\beta_{2} I N D S H+\beta_{3} F D I+\beta_{4} T E C+\beta_{5} U R B A N+\varepsilon_{i t}
$$

where $G E E_{i t}$ represents the green economy efficiency of the i-province in t-year, $\beta_{i}$ is the regression coefficient and $\varepsilon_{i t}$ is random error.

\subsection{Results ayalysis}

This study use STATA13.0 to measure the factors that impact green economic development efficiency, the results shown in Table 3.

Table 3 Tobit model estimates

\begin{tabular}{ccccc}
\hline Variables & Upstream & Midstream & Downstream & $\begin{array}{c}\text { Yangtze River } \\
\text { Economic Belt }\end{array}$ \\
\hline LnGDP2 & -0.3042 & 0.0008 & -0.0040 & -0.0028 \\
& $(-0.54)$ & $(0.26)$ & $(-1.79)^{*}$ & $(-1.34)^{*}$ \\
IND & 0.1044 & -0.4081 & -0.5519 & -0.3315 \\
& $(0.67)$ & $(-5.26)^{* * *}$ & $(-2.88)^{* * *}$ & $(-2.4)^{* *}$ \\
KL & 0.0474 & -0.002 & 0.0124 & -0.0022 \\
FDI & $(2.99)^{* * *}$ & $(-7.67)^{* * *}$ & $(0.67)$ & $(-3.21)^{* * *}$ \\
& -2.9084 & -5.4701 & -6.1989 & -6.1575 \\
TEC & $(-1.82)^{*}$ & $(-2.22)^{* *}$ & $(-1.82)^{*}$ & $(-5.71)^{* * *}$ \\
& -0.7415 & -0.2159 & -0.2548 & -0.7617 \\
URBAN & $(-6.54)^{* * *}$ & $(-0.75)$ & $(-0.41)$ & $(-3.05)^{* * *}$ \\
& -1.0012 & -0.3788 & -1.1429 & 0.0109 \\
constant & $(-4.09)^{* * *}$ & $(-5.39)^{* *}$ & $(-1.25)^{* * *}$ & $(0.11)$ \\
& 1.2475 & 1.3537 & 2.0585 & 1.2044 \\
Log.L & $(17.41)$ & $(21.45)$ & $(3.61)$ & $(14.66)$ \\
\hline
\end{tabular}

Notes: ${ }^{* *}$ Significant at the 1 percent level. ${ }^{* *}$ Significant at the 5 percent level. ${ }^{*}$ Significant at the 10 percent level. Zvalue of test statistics are shown in parentheses.

Table 3 shows the results of the model. From the Yangtze River economic belt zone, the coefficient of (InGDP) ${ }^{2}$ is negative (significantly at 1 percent level), indicating that there is an "inverted U" relationship between green economic efficiency and per capita GDP, that is, with the economic development, green economic efficiency showed a trend of increasing at first and decreasing later, it will reach the peak and then decline, which verified the existence of Kuznets curve. For the structural factors, the coefficient of industrial structure (the proportion of secondary industry) and endowment structure are significantly negative, and the impact of industrial structure coefficient is relatively stronger, indicating that the improvement of green economic efficiency on the one hand need to speed up industrial restructuring, control the secondary industry Scale, vigorously develop the tertiary industry; on the other hand need a reasonable allocation of capital and labor endowments, encourage technological innovation. FDI has a significant negative effect on green economic efficiency, and the coefficient is large, indicating that bringing in foreign investment has a significant negative effect on green economic efficiency, which confirms the "pollution paradise" hypothesis and indicates that the Yangtze River economic zone needs to strengthen the screening of foreign-funded enterprises and supervision. The coefficient of investment in science and technology is significantly negative, which shows that increasing investment in science and technology has a negative impact on green economic efficiency. The coefficient of urbanization is positive, but not significant, indicating that the positive impact of the urbanization process on the green environmental efficiency level is not significant. Therefore, in the further development of urban construction process, the need to actively promote energy-saving emission reduction facilities, establish environmental awareness and reduce waste of resources. 
For the upstream district, FDI, endowment structure, technology investment and urbanization level have a significant impact on the green economic efficiency. The industrial structure has a significant impact on the middle and lower reaches of the Yangtze River, but not significant for the upstream area, reflecting that more attention should be paid on structural adjustment. Urbanization level has a bigger impact on the downstream areas than up and midstream areas, which may be due to the higher level of urbanization in the downstream areas, the development of the city has brought environmental negative effects.

\section{Conclusions and policy implications}

This study has measured the green economic efficiencies of 11 provinces and cities in the Yangtze River Economic Zone during $2005-2014$ by DEA two-stage model and analyzed the influence factors by Tobit panel data model. The obtained results are as follows:

(1) The overall economic efficiency of the Yangtze River economic zone is good. Shanghai and Jiangxi showed an upward trend in the past decade, and Shanghai reached the basic effective state after 2009. The green economic efficiency of Jiangsu is decreasing first and rising later, while Anhui and Hubei showed a decreasing trend. As for Zhejiang, Hunan, Guizhou and Yunnan province, is basically in the effective state. Chongqing's green economic efficiency value showed a U-shaped growth, 2008 is lowest.

(2) There are differences in the factors affecting the green economic efficiency of different watersheds upstream and downstream. Overall there is an "inverted U" relationship between green economic efficiency and per capita GDP, and urbanization has a significant positive effect on green economic efficiency The role of foreign direct investment, structural factors, science and technology, pollution control investment have a negative effect.

Based on the above conclusions, we can formulate the following policy recommendations to explore effective ways for improving green economic efficiency narrowing the regional gap:

(1) We should pay attention to improve the efficiency of resource use and environmental management but not one-sided pursuit economic development speed. From the "inverted U-shaped" relationship between green economic efficiency and per capita GDP, all regions should balance the relationship between economic growth and environmental protection, to achieve the win-win situation of economic growth and environmental optimization, and ultimately achieve sustainable economic development.

(2) The industrial structure and the direct use of foreign capital have a significant impact on the green economic efficiency. Therefore, the government can guide enterprises to walk a new road to industrialization through active economic policies, control the development of the secondary industry, vigorously develop the tertiary industry, transform the economic growth mode, improve the screening of foreign-funded enterprises and environmental supervision.

(3) Under the premise of maintaining the rapid economic development of the downstream areas, make relevant economic policies according to local conditions to promote the rapid growth of upstream and midstream areas, narrow the regional gap. Meanwhile, establish and improve the environmental resource allocation system, leave out the error saying -"The government is responsible for the environmental protection, while economy rely on market". Under the market economy condition, arouse the enthusiasm of the economic entities through the incentive and restraint mechanisms, put environmental protection and local economic growth goals together to achieve the harmony and unity of economic development and ecological environment.

\section{REFERENCES}

1. Charnes A, Cooper W, 1978 Rhodes E. Measuring the efficiency of decision making units", European Journal of Operational Research[J]. 2(6),429-444.

2. Chow. G, A.Lin. 2003 Accounting for Economic Growth in Taiwan and Mainland China: A Comparative Analysis[J]. Journal of Comparative Economics. 30(3),507-530.

3. ChungY.H, R. Fare,S. Grosskopf,1997Productivity and Undesirable Outputs: A Directional Distance Function Appr oach[J]. Journal of Environmental Management. 51,229-240.

4. Hailu. A, Veeman.T.S. 2001 Non-parametric productivity analysis with undesirable outputs: an application to the Canadian pul Pand paper industry [J]. American Journal of Agricultural Economics. 83(3),605-616.

5. Liu X.C, Qian Z.M. 2013 Study on energy saving with Chinese regional energy-economic efficiency analysis based on the SBM model. Advanced Materials Research. (648), 247-250.(In Chinese)

6. QIAN Zhengming, LIU Xiaochen. 2013 Regional Differences in China's Green Economic Efficiency and Their Determinants[J]. China Population, Resources and Environment. 7(23),104-109. (In Chinese)

7. QIAN Zhengming, LIU Xiaochen. 2014 A Study of regional Differences and Convergence of Green Economic Efficiency in China[J]. Journal of Xiamen university (Arts\&Social Sciences). 1,110-118. (In Chinese)

8. Shan Haojie. 2008 Reestimating the Capital Stock of China:1952-2006. The Journal of Quantitative \& Technical Economics. (10),17-31. (In Chinese) 
9. Wang Bing, Huang Renjie. 2014 Regional Green Development Efficiency and Green Total Productivity Growth in China: 2000-2010: Base on Parametric Metafrontier Analysis[J]. Industrial Economic Review. (1),16-35. (In Chinese)

10. Wang Bing, Liu Guangtian. 2015 Energy conservation and emission reduction and China's green economic growth-Based on a total factor productivity Perspective[J]. China Industrial Economics.5(5),57-69. (In Chinese)

11. Wang Bing, Wu Yanrui, Yan Pengfei. 2010 Environment Efficiency and Environmental Total Factor Productivity Growth in China's Regional Economies[J]. Economic Research Journal.(5),95-109. (In Chinese)

12. Wang Jun, Geng Jian. 2014 Analysis and Empirical Study on China Green Economic Efficiency[J] On Economic Problems.(4),52-55. (In Chinese)

13. Wang Xiaoyun, Wei Qi, Hu Xianhui. 2016 Comprehensive Evaluation of Cities' Green Economy Efficiency and Spatial and Temporal Differentiation in China: Based on the DEA-BCC and Malmquist Model. Ecological Economy, 3(32),40-45.

14. Wang Zhigang, Gong Liutang, Chen Yuyu. 2006 China's Regional Differences in Technical Efficiency and the Decomposition of Total Factor Productivity Growth (1978-2003)[J]. Social Sciences in China.(2),55-66. (In Chinese)

15. Yan Pengfei, Wang Bing. 2004 Technical. Efficiency, Technical Progress \&Productivity Growth: An Empirical Analysis Based on DEA[J]. Economic Research Journal. (12),56-62. (In Chinese)

16. Yang Long, Hu Xiaozhen. 2010 Analysis on regional difference and convergence of the efficiency of China's green economy based on DEA[J]. Eeconomist. (2),46-54. (In Chinese)

17. Yuan Peng, Cheng Shi. 2011 Examining Kuznets Curve in Environmental Efficiency of China's Industrial Sector[J]. China Industrial Economics.2(2),79-88. (In Chinese)

18. Zhou.P, Ang B.W, Poh K.L.2008 A survey of data envelopment analysis in energy and environment studies[J].European Journal of Operational Research. (189),1-18.

\section{Author' biography with Photo}

Jiani WU, Master student in the School of Economic and Resource Management at Beijing Normal University. She majored in regional economics, and research area is regional green development

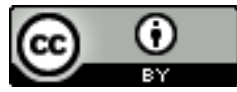

This work is licensed under a Creative Commons Attribution 4.0 International License.

DOI: $10.24297 /$ jssr.v11i2.6049 